http://jmscr.igmpublication.org/home/ ISSN (e)-2347-176x ISSN (p) 2455-0450

crossref DOI: https://dx.doi.org/10.18535/jmscr/v7i8.89

\title{
Advantages of Diagnostic Laparoscopy in Chronic Abdominal Conditions - A Retrospective Study
}

\author{
Authors \\ Dr Angeline Vincent ${ }^{1}$, Dr Usha ${ }^{2 *}$ \\ ${ }^{1}$ Assistant Professor, ${ }^{2}$ Professor \& HOD, Department of Surgery \\ Kanyakumari Government Medical College Hospital, Tamil Nadu, India \\ *Corresponding Author \\ Dr Usha, MS Surgery \\ Department of Surgery, Kanyakumari Government Medical College Hospital, Tamil Nadu, India
}

\begin{abstract}
Diagnostic laparoscopy is defined as a minimally invasive surgical procedure that allows the visual examination and documentation of intra abdominal organs in order to detect any pathology. We studied 100 patients over a period of 3 years. $90 \%$ of our study patients were above 40 years. $43 \%$ of our patients had chronic abdominal pain, 27\% of presented with subacute intestinal obstruction. 14\% had surgical jaundice, $12 \%$ of patients had loss of appetite and weight, $4 \%$ of patients had occult hernias. Totally 100 diagnostic laparoscopies were done. Diagnostic laparoscopy alone established the diagnosis is $37 \%$. Diagnostic laparoscopy and biopsy established the diagnosis in 98\%. Diagnostic laparoscopy failed to yield the diagnosis $n 2 \%$. The sensitivity of this procedure is $98 \%$. Its value is higher in malignant than inflammatory lesions because of extensive adhesions met in the latter condition. 27 patients who would ordinarily need explorative lapatomy had the same information gained by the use of diagnostic laparoscopy. $98 \%$ diagnostic conformation achieved in our series speaks for the advantage of laparoscopy as a diagnostic tool in chronic abdominal conditions. The $P$ value $<0.01$. Though the invasive procedure, diagnostic laparoscopy is easy to perform and safe in expert hands.

Keywords: Diagnostic laparoscopy, chronic abdominal pain, surgical jaundice, subacute intestinal obstruction.
\end{abstract}

\section{Introduction}

Because of the morbidity associated with explorative laparotomy, we searched for advantageous in the use of elective diagnostic laparoscopy as a diagnostic tool in chronic abdominal disorders, in Kanyakumari Medical College Hospital, Tamil Nadu, India a tertiary care centre. Diagnostic laparoscopy is a minimally invasive surgical procedure that allow the visual examination and documentation of intra abdominal organs in order to detect any pathology. Aims of this study is (1) To make a definitive diagnosis (2) To assess the extent of the disease. (3) To confirm the clinical and radiological findings in doubtful cases. (4) To give effective relief to the patients where possible. Diagnostic laparoscopy is defined as a minimally invasive procedure performed in patients who have equivocal diagnosis to arrive at a definitive diagnosis. 


\section{Materials \& Methods \\ Design of Study}

Time period of study - Jan.2016 to Jan.2018

Age of patients - $\quad 25$ years to 65 years

Gender of patients - Male \& Female

Place - Kanyakumari Government Medical

College, Hospital

\section{Inclusion Criteria}

1. Chronic abdominal pain

2. Intra abdominal lymphadenopathy of unknown etiology

3. Surgical Jaundice

4. Ascites of unknown etiology

5. Vague abdominal mass

6. Subacute intestinal obstruction

7. Miscellaneous conditions

\section{Exclusion Criteria}

1. Mechanical or paralytic ileus

2. Coagulopathy

3. Severe cardiopulmonary disease

4. Abdominal wall infection

5. Pregnancy

6. Generalized peritonitis

7. Massive Ascites

All patients in the study are subjected to, History taking, Physical examination, Laboratory tests CHG, LFT, Blood sugar, Renal function tests, Bleeding time, Clotting time, ECG, Radiology X- ray chest, Contrast radiology if needed, Non invasive imaging USG, CT, Diagnostic laparoscopy, Follow up.

\section{Procedure}

Laparoscopic examination of peritoneal surface, diaphragm, liver, gall bladder, spleen, stomach, small intestine, colon, pelvic organs and retroperitoneal organs. Take biopsy of any mass \& collect intraperitoneal fluid for cytology.

\section{Abnormal Study Includes}

1. Intra abdominal mass

2. Metastatic cancer

3. Fluid in peritoneal cavity

4. Adhesions

5. Endometriosis

6. Pelvic inflammatory disease

7. Occult hernia

\section{Analysis of Data}

Table - 1

\begin{tabular}{|l|c|c|}
\hline $\begin{array}{l}\text { S. } \\
\text { NO }\end{array}$ & MODE OF PRESENTATION & $\begin{array}{c}\text { NO OF } \\
\text { CASES }\end{array}$ \\
\hline 1 & Chronic abdominal pain & 43 \\
\hline 2 & Sub Acute Intestinal Obstruction & 27 \\
\hline 3 & Loss of Weight Loss of appetite & 12 \\
\hline 4 & Occult Hernias & 3 \\
\hline 5 & Faceal fistula & 1 \\
\hline 6 & Jaundice & 14 \\
\hline
\end{tabular}

\section{Mode Of Presentation}

- Chronic Abdomina pain

- Sub Acute Intestinal Obstructio

- Loss of Weight,Loss of Appetite

- Occult Herni

- Faceal fistula

- Jaundice

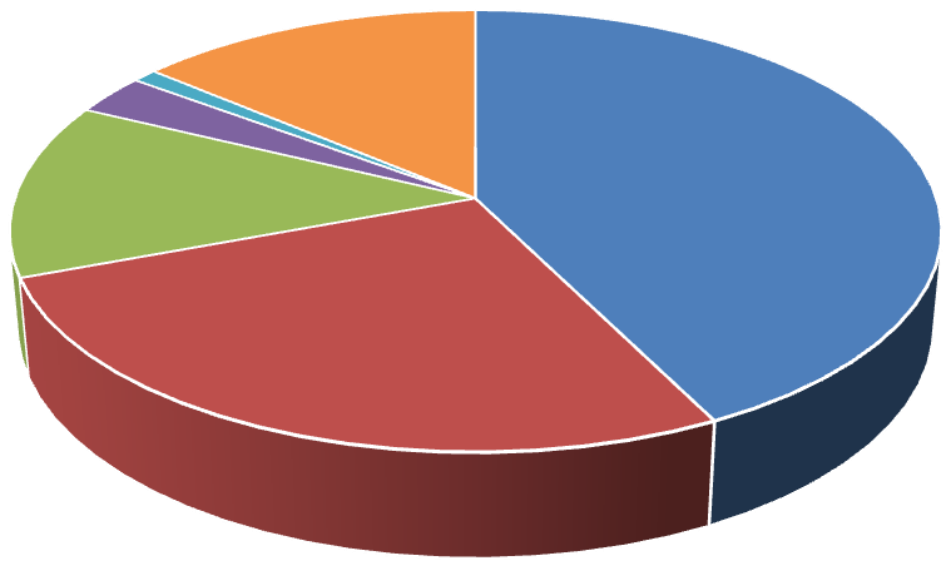


Table - 2

\begin{tabular}{|l|c|c|}
\hline S. NO & CLINICAL ABDOMINAL FINDINGS & NO OF CASES \\
\hline 1 & Tenderness & 36 \\
\hline 2 & Mass Abdomen & 16 \\
\hline 3 & Hard nodular Hepatomegaly & 10 \\
\hline 4 & Ascites & 4 \\
\hline 5 & Absent tests in Scrotum in normal position & 3 \\
\hline
\end{tabular}

Clinical Abdominal Findings

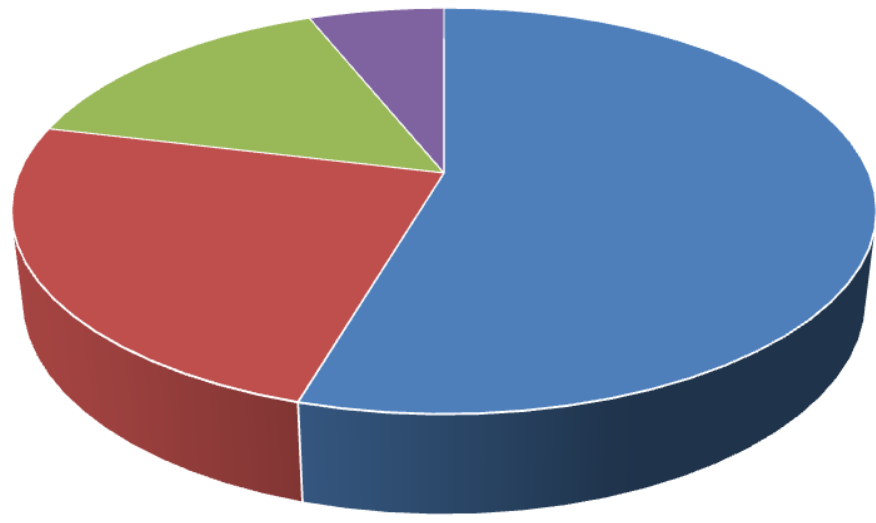

- Tenderness

- Mass Abdomen

- Hard Ndulatr Hepatomegaly

- Ascites

- Absent tests in Scrotum in normal position

Table $-\mathbf{3}$

\begin{tabular}{|l|c|c|}
\hline S. NO & EXTRA ABDOMINAL & NO OF CASES \\
\hline 1 & Enlargement of Virchow's node & 2 \\
\hline 2 & Jaundice & 14 \\
\hline
\end{tabular}

Table -4

\begin{tabular}{|l|c|c|}
\hline S. NO & TYPES OF ANESTHESIA & NO OF CASES \\
\hline 1 & General Anaesthesia & 100 \\
\hline
\end{tabular}

Table -5

\begin{tabular}{|l|c|c|}
\hline S. NO & LAPAROSCOPIC FINDINGS & NO OF CASES \\
\hline 1 & Adhesions & 25 \\
\hline 2 & Enlarged mesenteric nodes & 19 \\
\hline 3 & Tubercles over mesentry, peritoneum & 14 \\
\hline 4 & Nodules over liver & 16 \\
\hline 5 & Intra abdominal testes & 3 \\
\hline 6 & Secondary Deposits over & 11 \\
\hline 7 & Malrotation of gut & 1 \\
\hline 8 & Intusussception & 2 \\
\hline 9 & Richter's hernia & 3 \\
\hline 10 & Absent Gall bladder & 1 \\
\hline 11 & Mass in RIF (Complex) & 2 \\
\hline 12 & Persistent Vitellointestinal band & \\
\hline
\end{tabular}




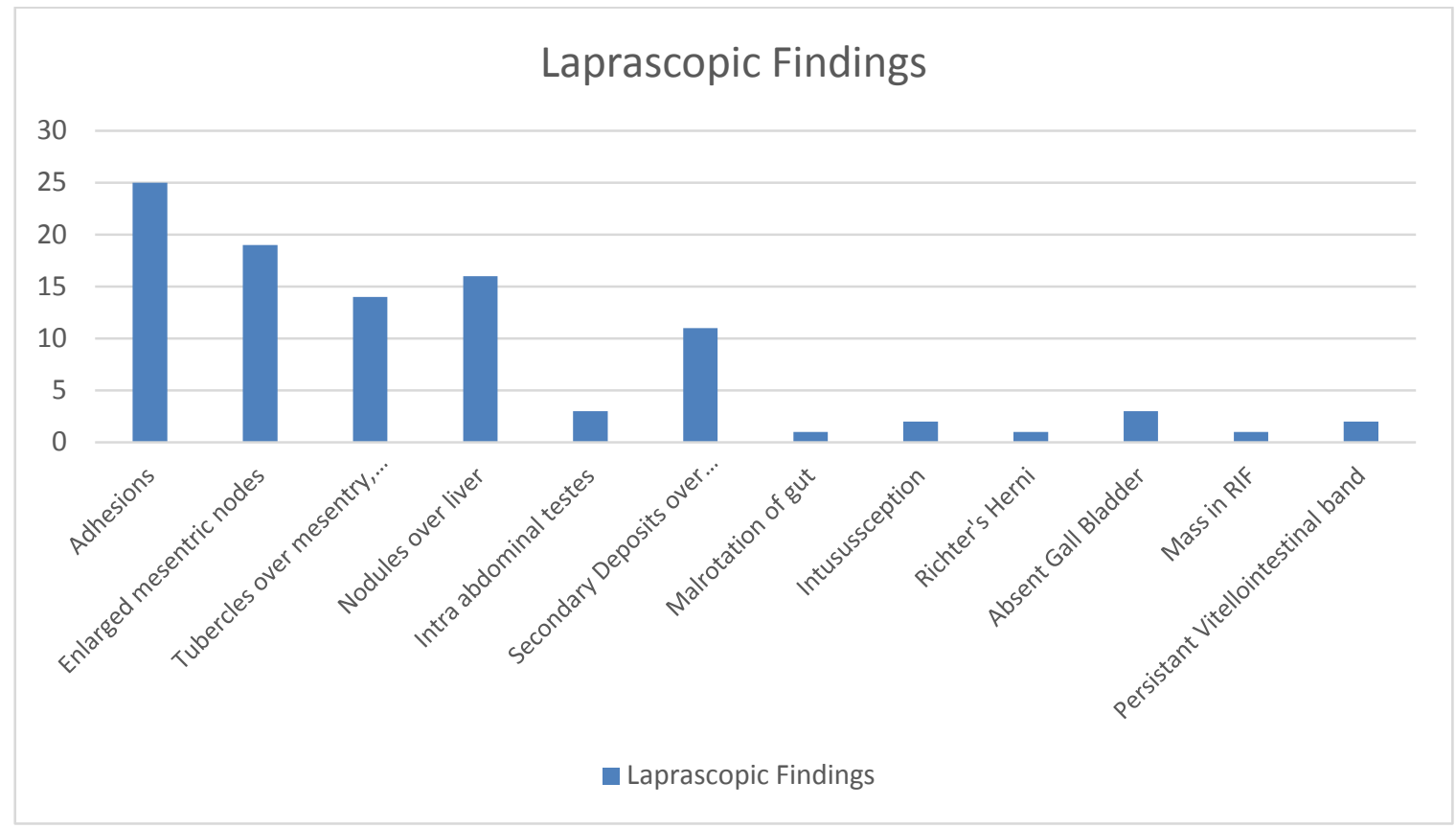

Table - 6

\begin{tabular}{|l|c|c|}
\hline S. NO & NO OF BIOPSIES & NO OF CASES \\
\hline 1 & Enlarged mesenteric / Paraaortic node / Tubercles & 33 \\
\hline 2 & Nodules over liver & 16 \\
\hline 3 & Mass in RIF (Complex) & 1 \\
\hline 4 & Secondary Deposits over peritoneum & 11 \\
\hline & TOTAL & 61 \\
\hline
\end{tabular}

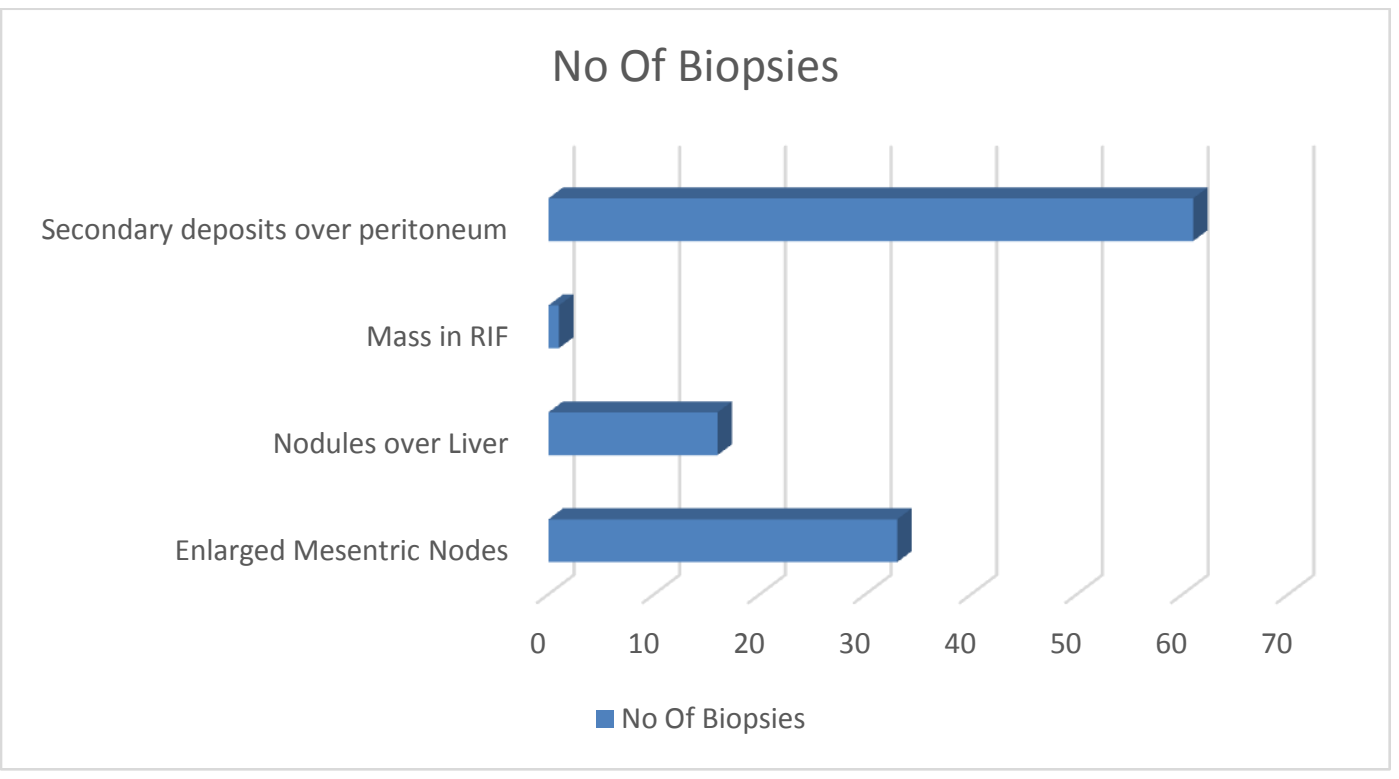

Table -7

\begin{tabular}{|l|c|}
\hline TOTAL NO OF CASES & TOTAL NO OF COMPLICATION \\
\hline 100 & NIL \\
\hline
\end{tabular}

\section{Discussion}

In my study 43 patients presented with chronic abdominal pain. The diagnosis was established in all but one patient. 27 patients presented with features of subacute intestinal obstruction. 25 of these patients had post operative adhesions as the 
cause of the subacute intestinal obstruction. Two patient had persistent vitellointestinal band. One patients had partial malrotation of the gut. Another patient had intusussception. Of the 12 patients who presented with loss of appetite and loss of weight 4 had TB abdomen. 8 patients had hepatocellular carcinoma. 16 patients presented with mass abdomen and 1 proved to be endometriosis and 10 patient had hyperplastic iteocaecal tuberculosis. Of the 10 patients who presented with nodular hepatomegaly 4 had hepatocellular carcinoma and 6 patient had cirrhosis of the liver. Jaundice was the indication for diagnostic laparoscopy in 14 patients and they proved to have hepatocellular carcinoma on liver biopsy. 4 patients had minimal ascities and fluid aspirated for cytology showed adenocarcinoma cells in one patient. Diagnostic laparoscopy showed nodular hepatic surface and biopsy proved the case as hepatocellular carcinoma. In 3 patients with absent testes in the normal scrotal position, diagnostic laparoscopy revealed intra abdominal testes. 3 patients presented with occult hernia and two were proved to be congenital hernias on diagnostic laparoscopy. One patient presented with faecal fistula and a Richter's hernia was seen on diagnostic laparoscopy. Diagnostic laparoscopy was performed in 100 patients and the objective diagnosis was established in 69 patients by Diagnostic laparoscopy alone. Biopsy along with Diagnostic laparoscopy established the diagnosis in 30 patients. The procedure did not provide a diagnosis in one patient. In three patients laparotomy was resorted to following Diagnostic laparoscopy. There were no complications observed.

\section{Conclusion}

Totally 100 diagnostic laparoscopies were done in my study. Diagnostic laparoscopy alone established the diagnosis in 37 patients Diagnostic laparoscopy + biopsy established the diagnosis in 61 patients. Diagnostic laparoscopy failed to yield a diagnosis in 2patient (2\%). These figures indicate the sensitivity (98\%) of this procedure. Its value is higher in malignant than inflammatory lesions because of extensive adhesions met in the latter condition. In 10 patients who would ordinarily need exploratory laparotomy had the same information gained by the use of diagnostic laparoscopy. The fact that $98 \%$ diagnostic confirmation achieved in our series speaks for the advantage of laparoscopy as a diagnostic tool in chronic abdominal conditions. The $\mathrm{P}$ Value < 0.01Though an invasive procedure Diagnostic laparoscopy is easy to perform and safe in expert hands.

\section{References}

1. N.Engl J. Med. 1994 July 7; (1) Laparoscopic general surgery

2. World J Surg 2006 Apr; 30 (4): 535 - 40 Laparoscopic lysis of adhesions

3. Short practice of surgery, Bailey and Love's $-28^{\text {th }}$ Edition; Page No. 107

4. Principles of surgery - schwartz's $-8^{\text {th }}$ Edition pp 379-381 Blair A.Jobe and John G. Huntere

5. Text book of surgery - sabiston $-17^{\text {th }}$ Edition Cralg Change. M.D. and Robert V.Rege M.D. Chapter - 18 Page No.445

6. Philips P A AmaralJF : Abdominal access complications in laparoscopic surgery. Jam coll Surg 19: 525 - 536, 2001

7. Boyd Jr. WP, Nord HJ, Diagnostic laparoscopy. Endoscopy 2000;32:153- 158

8. Schneider ARJ, Eickhoff A, Arnold JC, Reimann JF. Diagnostic laparoscopy. Endoscopy 2001; 33: 55-59

9. Easter DW, Cuschieri A, Nanthanson LK, Lavelle-Jones M. The utility of diagnostic laparoscopy for abdominal disorders: audit of 120 patients. Arch Surg 1992; 127: 379383

10. Hossain J, Al-Aska, AK Al Mofleh I. Laparoscopy in tuberculous peritonitis. J R Soc Med 1992; 85: 89-91. 